\title{
Convection in a Parameterized and Superparameterized Model and Its Role in the Representation of the MJO
}

\author{
HONGYAN ZHU AND HARRY HENDON \\ Bureau of Meteorology, CAWCR, Melbourne, Victoria, Australia \\ CHRISTIAN JAKOB \\ School of Mathematical Sciences, Monash University, Melbourne, Victoria, Australia
}

(Manuscript received 3 February 2009, in final form 30 March 2009)

\begin{abstract}
The behavior of convection and the Madden-Julian oscillation (MJO) is compared in two simulations from the same global climate model but with two very different treatments of convection: one has a conventional parameterization of moist processes and the other replaces the parameterization with a two-dimensional cloud-resolving model, the so-called superparameterization. The different behavior of local convection and the MJO in the two model simulations reveals that the accurate representation of the following characteristics in the modes of convection might contribute to the improvement of the MJO simulations: (i) precipitation should be an exponentially increasing function of the column saturation fraction, (ii) heavy precipitation should be associated with a stratiform diabatic heating profile, and (iii) there should be a positive relationship between precipitation and surface latent heat flux.
\end{abstract}

\section{Introduction}

The Madden-Julian oscillation (MJO) is the dominant mode of tropical intraseasonal variability (e.g., Madden and Julian 1994) and it affects a wide range of tropical weather including the onset and breaks of the Indian and Australian summer monsoons (e.g., Yasunari 1979; Hendon and Liebmann 1990; Wheeler and McBride 2005; Goswami 2005) and the formation of tropical cyclones (e.g., Liebmann et al. 1994; Bessafi and Wheeler 2006). The MJO is a major modulator of tropical diabatic heating and as such plays an important role in driving teleconnections throughout the tropics and into the extratropics (e.g., Weickmann et al. 1985). Furthermore, the MJO is associated with the triggering and termination of some El Niño events (e.g., Kessler et al. 1995; McPhaden 2008; Hendon et al. 2007).

Given the prominent role of the MJO with regard to global weather and climate, it is imperative that global climate models (GCMs) adequately simulate the MJO in

Corresponding author address: Dr. Hongyan Zhu, Bureau of Meteorology, CAWCR, GPO Box 1289, Melbourne VIC 3001, Australia.

E-mail: h.zhu@bom.gov.au order to faithfully represent the full spectrum of climate variability. However, GCMs continue to have difficulty in simulating many of the important characteristics of the MJO. Typically, model MJOs are too weak, especially the convective component, and they propagate eastward too fast (e.g., Hayashi and Sumi 1986; Lau et al. 1988; Slingo et al. 1996; Maloney and Hartmann 2001). Although some recent progress in the simulation of the MJO has been reported (e.g., Waliser et al. 2003; Zhang et al. 2006), the state-of-the-art coupled oceanatmosphere GCMs participating in the Intergovernmental Panel on Climate Change (IPCC) Fourth Assessment Report (AR4) all continue to have significant problems in representing the MJO (Lin et al. 2006).

The simulation of the MJO in GCMs has shown great sensitivity to the details of convective parameterization (e.g., Wang and Schlesinger 1999; Maloney and Hartmann 2001), which thus points to the representation of tropical convection as being an important contributor to the generally poor simulations of the MJO in current GCMs. Diagnosing the problems of a particular convective parameterization that leads to the poor simulation of the MJO has, however, proved to be a difficult challenge. To put another way, it is not obvious which aspects of convective behavior need to be faithfully 
represented by a parameterization in order to adequately represent the MJO (and other modes of largescale organized convection). One common finding from modeling experiments is the sensitivity of the simulated MJO to threshold conditions for the onset of convection: higher thresholds typically result in better organized and stronger MJOs [e.g., Tokioka et al. (1988), using a minimum entrainment threshold, and Wang and Schlesinger (1999), with a relative humidity threshold in the convection scheme]. However, this sensitivity is not universal; the results of Maloney and Hartmann (2001) suggest rather that it is the realistic simulation of the mean humidity above the boundary layer and its evolution through the life cycle of the MJO (e.g., as a result of evaporation of convective precipitation) that is crucial for a faithful simulation of the MJO.

To build on sensitivity studies such as those by Maloney and Hartmann (2001), we will examine some possible critical dependencies for tropical convection on a variety of parameters, including column-integrated humidity (e.g., Bretherton et al. 2004) and surface moisture fluxes (e.g., Raymond et al. 2003), that may be related to the evolution of the MJO. Rather than conduct sensitivity experiments with a single convection parameterization, we will make use of two simulations from the same GCM but with two very different treatments of convection and very different simulations of the MJO. Our focus will be on diagnosing the local controls of tropical convection and associated rainfall as resolved on GCM grids, which is thus naturally comparable to observed behavior as resolved, for instance, by global satellite products with similar resolutions. The aim of this analysis is to provide a better understanding of those aspects of convective behavior that are critical for a proper simulation of the MJO.

\section{CAM and SP-CAM models}

Our analysis is based on Atmospheric Model Intercomparison Project (AMIP)-style simulations of the Community Atmosphere Model (CAM), version 3 (Collins et al. 2004) and the "superparameterized" version of the same model (SP-CAM), which were performed at Pacific Northwest National Laboratories (Marchand et al. 2009). The standard CAM simulation uses the Zhang and McFarlane (1995) method for convective parameterization, which is a mass flux scheme with a closure based on the assumption that convection consumes large-scale convective available potential energy (CAPE) and acts to return the atmosphere to a neutrally buoyant state over a given convective adjustment time scale. The SP-CAM is based on the multiscale modeling framework (MMF), which is a new approach to climate modeling (Grabowski 2001; Khairoutdinov and Randall 2001; Khairoutdinov et al. 2005) in which cloud processes are treated more explicitly by replacing the parameterizations of a GCM with a 2D cloud system-resolving model at each grid point of the GCM.

Details of some comparisons between the simulations using the CAM and SP-CAM can be found in Khairoutdinov et al. (2005) and DeMott et al. (2007). Some improvements of the simulated tropical climate in SP-CAM over CAM reported in these studies are 1) an improved diurnal cycle of precipitation over land, 2) a more realistic distribution of cirrus cloudiness, 3) a better simulation of heavy rainfall, and 4) a more realistic relationship among precipitation and lower- and upper-level humidity. Although many aspects of the climate related to clouds and precipitation are reported to have improved in the SP-CAM over the standard CAM, there are still several problems in the SP-CAM simulation that require explanation. These include a high rainfall bias in the western Pacific, too high a zonal wind variability in the tropics, an overactive Indian monsoon, and a failure to simulate light rain rates.

One important result from the study of Khairoutdinov et al. (2005) is that the SP-CAM produces a more realistic MJO, whereas the MJO is completely absent from the CAM. Thus, the simulations with the SP-CAM and CAM provide a potentially useful test bed to explore the link between the behavior and controls of subgrid-scale convection and the ability to simulate the MJO. We will assess and compare the behavior of tropical convection in the two simulations, with the aim of elucidating those aspects of convection that might be associated with an improved simulation of the MJO. We also compare the model results with observations and to some previously published studies based on observed behavior.

The observation datasets for verification in this paper are the Global Precipitation Climatology Project (GPCP) daily precipitation with $1^{\circ}$ resolution (Adler et al. 2003); the daily mean latent heat flux from the Woods Hole Oceanographic Institution (WHOI) Objectively Analyzed Air-Sea Fluxes Project (OAFlux; Yu et al. 2008), also with $1^{\circ}$ resolution; and the 40-yr European Centre for Medium-Range Weather Forecasts (ECMWF) Re-Analysis (ERA-40) of winds, temperature, and moisture fields with $2.5^{\circ}$ resolution (Uppala et al. 2005). ERA-40 reanalyses are from a data assimilation system and therefore contain an optimal blend of model results and observations. For simplicity we will refer to the reanalyses as observations, acknowledging that they are not based on observations alone. Our results will show, however, that it is unlikely the model shortcomings we identify are an artifact of the use of ERA-40. For model simulations and observations, we 
use daily data for the period July 1998-June 2002 (the period of available model simulations). The model output is available on a $2.5^{\circ} \times 2.0^{\circ}$ grid.

\section{Results}

\section{a. Initial assessment of the $M J O$}

The simulation of the MJO in the two models is initially assessed using wavenumber-frequency spectral analysis (e.g., Salby and Hendon 1994). The analysis is applied to daily mean rainfall and zonal wind at $850 \mathrm{hPa}$ (hereafter U850) for the region $14^{\circ} \mathrm{S}$ to $14^{\circ} \mathrm{N}$, and, to focus on the MJO, we display the power for the equatorially symmetric components (e.g., Wheeler and Kiladis 1999). The observed MJO is characterized by a distinct spectral peak at eastward wavenumber 1 for zonal wind and eastward wavenumbers $1-3$ for precipitation at periods of 30-90 days (Fig. 1), which is consistent with observational analyses using longer records (e.g., Salby and Hendon 1994). The SP-CAM (Figs. 2a,b) exhibits a strong peak at MJO wavenumbers and frequencies for both U850 and precipitation. In fact, the peak power for U850 at eastward wavenumber 1 and a 50-day period is about 4 times greater than the observed, whereas the equivalent spectral peak for rainfall is about double of the observed value, which is somewhat unique for modern climate models (e.g., Maloney and Hartmann 2001; Zhang et al. 2006). Hence, the SP-CAM exhibits a very clear and pronounced MJO signal. Eastward power and westward power are both stronger in the SP-CAM compared to observation, but the ratio between eastward and westward power in SP-CAM is similar to that in observation. On the other hand, CAM has almost equal power in eastward and westward power, and the spectra appear red in frequency, with maximum power occurring at the lowest frequency and with no intraseasonal peak. Hence, we infer that the MJO is completely absent in the CAM simulation (Figs. 2c,d).

\section{b. Relationship between precipitation and column-integrated humidity}

Precipitation over the tropical oceans is observed to strongly vary with tropospheric humidity (e.g., Bretherton et al. 2004; Sherwood 1999). In particular, Bretherton et al. (2004) have highlighted a quasi-exponential relationship between the precipitation rate and column saturation fraction (hereafter saturation fraction). Raymond (2007), for instance, found that in a simple model the sensitivity of the convective parameterization to saturation fraction plays a key role in determining the time and space scales of tropical convective variability. In particular, the ability of the model to exhibit organization at time and space scales associated with the
MJO was shown to be sensitive to the humidity state of the atmosphere as represented by saturation fraction. Based on these studies, we begin our examination of convection behavior in the CAM and SP-CAM by investigating their representation of the relationship between saturation fraction and tropical precipitation.

Daily values of saturation fraction are computed as $r=W / W *$, where $W$ and $W *$ are the column-integrated water vapor mixing ratio and column-integrated saturated water vapor mixing ratio, respectively. Figure 3a shows observed and simulated daily mean precipitation in $5 \%$ bins of saturation fraction for tropical ocean points across the western Pacific/Indian Ocean warmpool region $\left(12^{\circ} \mathrm{S}-12^{\circ} \mathrm{N}, 60^{\circ}-180^{\circ} \mathrm{E}\right)$. The strong sensitivity of rainfall to saturation fraction as diagnosed by Bretherton et al. (2004) is reproduced here using different observed rainfall, moisture, and temperature datasets. In particular, precipitation is observed to become nonzero at about 0.5 saturation fraction and then increases nearly exponentially with saturation fraction until a slight flattening occurs above 0.8 saturation fraction.

In the CAM simulation, the onset of precipitation occurs at a lower saturation fraction than observed (less than 0.4 as compared to greater than 0.5 for observed), with most of the increase in precipitation occurring in the range of 0.4 and 0.75 , after which rainfall does not increase further with increases in saturation fraction (or even tails off). The shape of the rainfall-saturation fraction relationship in the CAM is, however, similar to the observed, although it is shifted to lower saturation fraction for the equivalent rainfall rate by about 0.2 . The SP-CAM shows a very different behavior to the CAM. Significant rainfall does not occur until the saturation fraction exceeds 0.6 , followed by a steeper-thanobserved increase of rainfall with saturation fraction that continues up to the highest rainfall rates, where the maximum rainfall rate at 0.95 saturation fraction is more than double the observed rate.

The frequency of occurrence of saturation fraction is shown in Fig. 3b. The observed distribution is strongly peaked with the mode near $0.7-0.75$, with a sharp decline toward higher saturation fraction (very few occurrences greater than 0.9) and a long tail toward lower saturation fraction. The CAM displays a much more symmetric and narrower distribution that is peaked at about 0.55 , with very few occurrences of saturation fraction greater than 0.7 , which is near the mode of the observed distribution. This narrower and drier distribution in the CAM might be indicative of convection being triggered too easily, thereby drying the atmosphere before it can reach saturation values of 0.7 and greater. The shape of the frequency distribution for the SP-CAM is closer to the observed, with a mode of about 


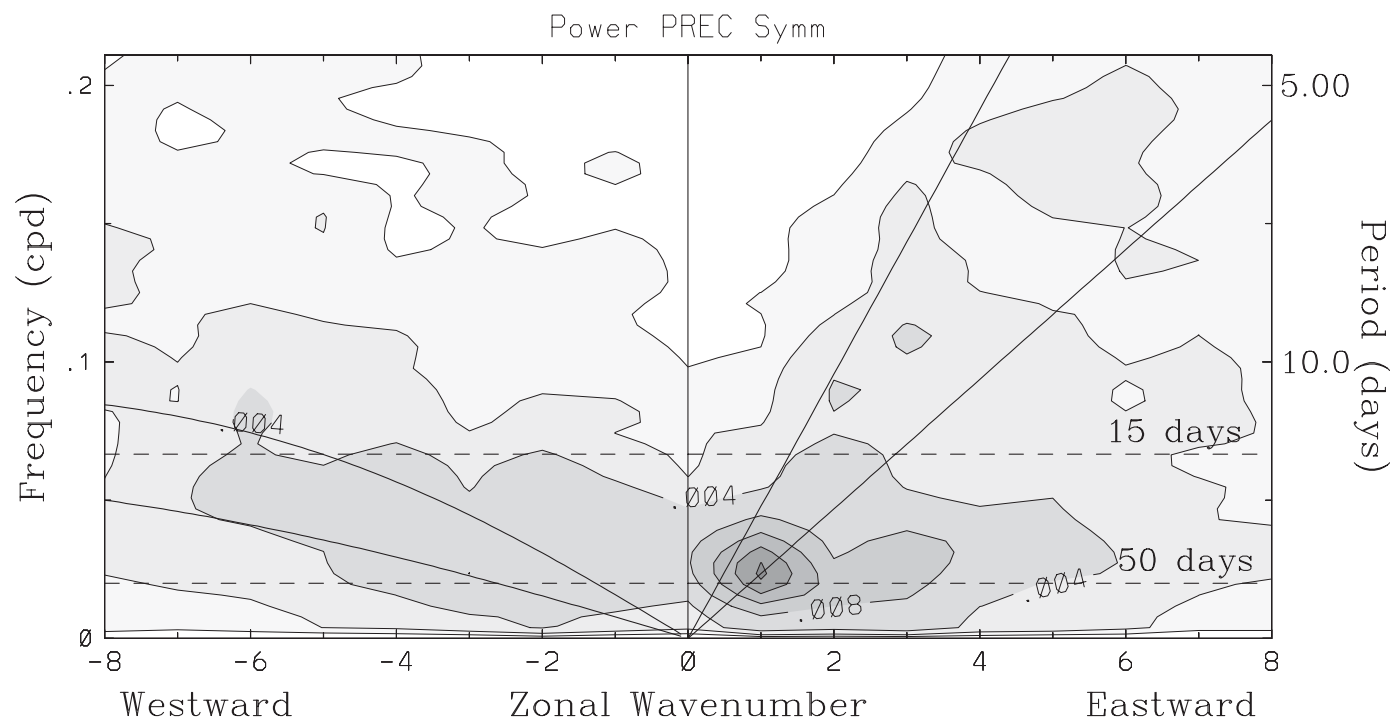

(a)

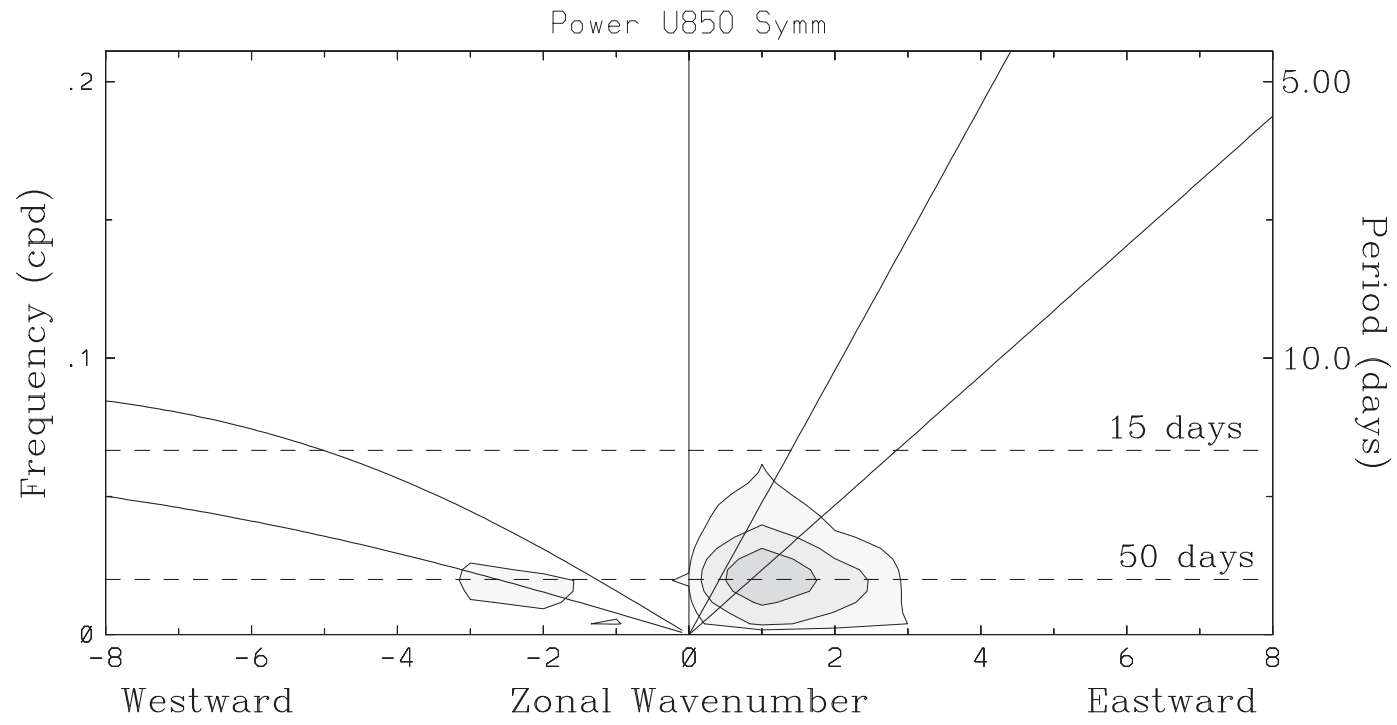

(b)

FIG. 1. The symmetric precipitation and U850 space-time power spectrum for observation for latitudes from $14^{\circ} \mathrm{S}$ to $14^{\circ} \mathrm{N}$. Contour interval (CI) for precipitation power is $0.004 \mathrm{~mm}^{2}$ day $^{-2}$, with additional contours of 0.002 and $0.001 \mathrm{~mm}^{2} \mathrm{day}^{-2}$; CI for U850 power is $0.02 \mathrm{~m}^{2} \mathrm{~s}^{-2}$, with additional contours of 0.005 and $0.001 \mathrm{~m}^{2} \mathrm{~s}^{-2}$. Superimposed are the theoretical shallow-water dispersion curves for the equatorial Rossby and Kelvin waves with equivalent depths of 25 and $50 \mathrm{~m}$.

0.75 , but the occurrence of saturation fraction greater than 0.75 drops off much more slowly than observed, displaying a significant number of occurrences of saturation fraction greater than 0.9 . There are also fewer occurrences of dry states (saturation fraction less than $0.5)$ than observed. Thus, the SP-CAM may have convection behavior opposite to that of the CAM, with convection being triggered only when the atmosphere has reached higher than observed saturation fraction.

This analysis of rainfall rate versus saturation fraction in the two simulations is consistent with the recent study of DeMott et al. (2007), who computed the probability distribution function of daily mean rainfall for 3 months in three geographic locations from simulations with the 


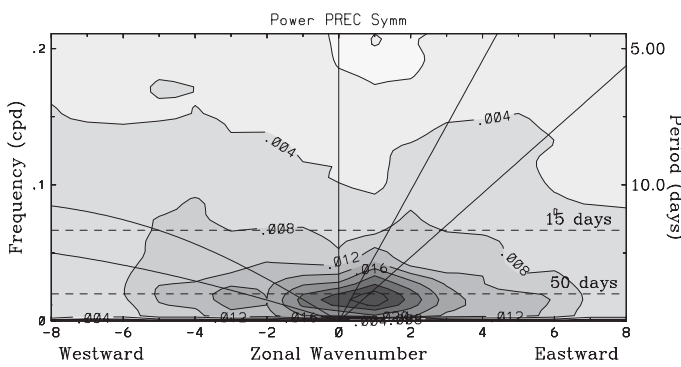

(a)

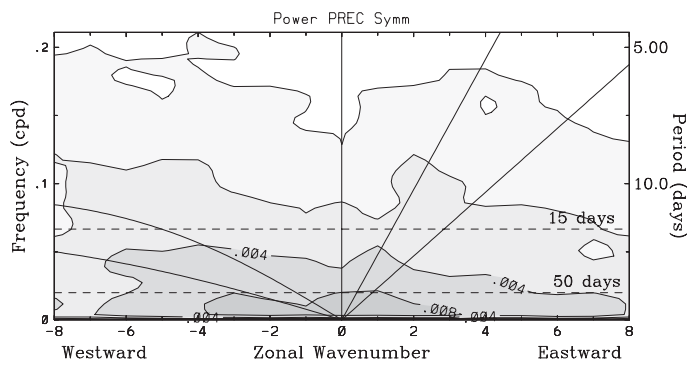

(c)

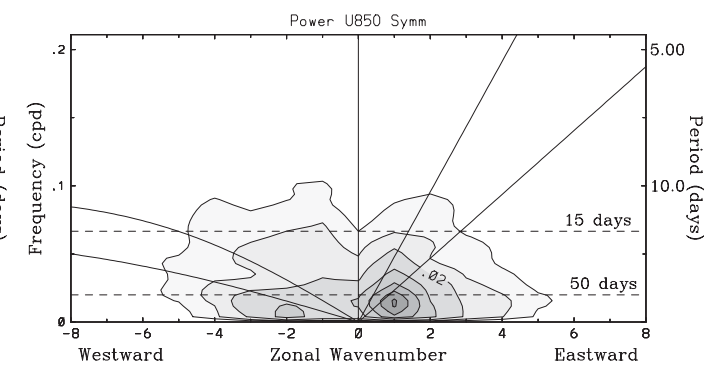

(b)

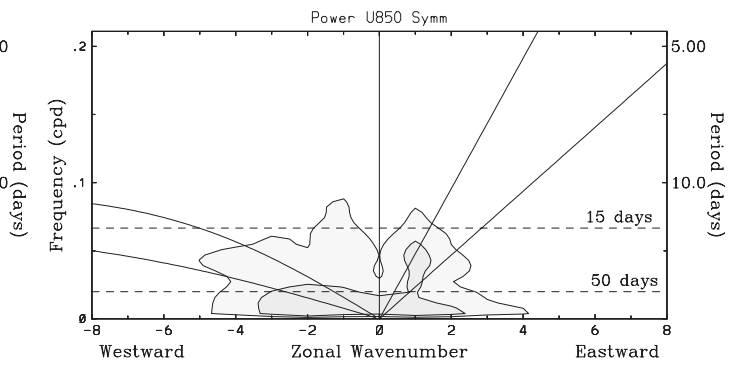

(d)

FIG. 2. As in Fig. 1, but for the (a),(b) SP-CAM and (c),(d) CAM simulations.

CAM and SP-CAM. They found that CAM produces too much light-to-moderate rainfall and not enough heavy rainfall, whereas the SP-CAM underestimates rain contributions from the lightest rainfall rates but more realistically simulates more intense rainfall events. From our analysis it appears that these more realistic high-intensity rainfall events occur in too moist of an atmosphere.

\section{c. Relationship between precipitation and vertical profile of humidity}

To better understand the differing relationships between rainfall rate and saturation fraction in the SP-CAM and CAM simulations, we investigate the relationship between rainfall rate and the vertical profile of humidity (mixing ratio). To do so, we calculate humidity anomalies (anomalies formed by removing the climatologically seasonal cycle and mean value over the 4 years) as a function of rainfall intensity. Instead of choosing arbitrary thresholds, we divide the rainfall rate into 10 equal bins (deciles) to represent the intensity of precipitation rate below, at, and above the average value. Note that the decile divisions are specific to each of the three rainfall datasets (GPCP, CAM, and SP-CAM) because each has a different rainfall distribution. The threshold

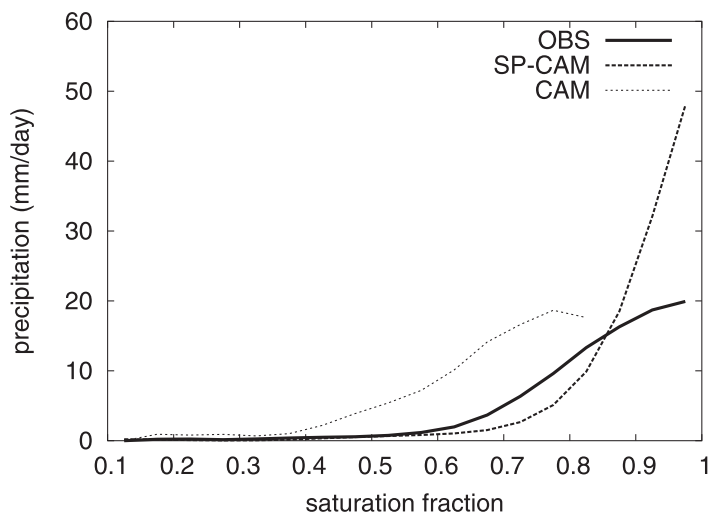

(a)

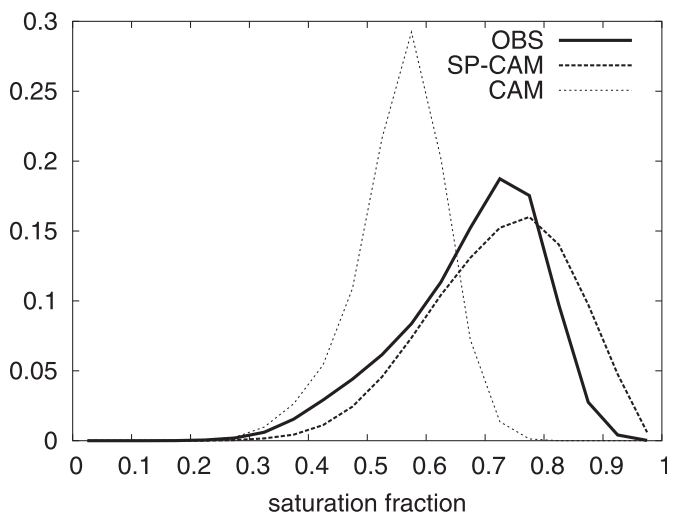

(b)

FIG. 3. (a) Mean daily precipitation composited into $5 \%$ bins of saturation fraction for tropical ocean grid points in the west Pacific and Indian Ocean warm-pool region $\left(12^{\circ} \mathrm{S}-12^{\circ} \mathrm{N}, 60^{\circ}-180^{\circ} \mathrm{E}\right)$ for SP-CAM, CAM, and observation. (b) Ratio of number of observations in each bin to the total number of data points. 
TABLE 1. List of end value of precipitation rate $\left(\mathrm{mm} \mathrm{day}^{-1}\right)$ for each decile.

\begin{tabular}{llllccrrrrr}
\hline \hline Experiment & 1 & 2 & 3 & 4 & 5 & 6 & 7 & 8 & 9 & 10 \\
\hline SP-CAM & 0.007 & 0.22 & 0.58 & 1.03 & 1.69 & 2.85 & 5.38 & 10.47 & 20.35 & 203.33 \\
CAM & 0.19 & 0.82 & 1.94 & 3.39 & 5.08 & 7.05 & 9.41 & 12.41 & 16.95 & 75.80 \\
OBS & 0.0 & 0.0 & 0.015 & 0.26 & 1.01 & 2.61 & 5.42 & 10.13 & 18.44 & 166.92 \\
\hline
\end{tabular}

values of the deciles of precipitation rate for each of the three datasets can be found in Table 1 .

Figure $4 \mathrm{a}$ shows the vertical profile of humidity anomalies binned into rainfall deciles derived from a combination of the GPCP dataset for precipitation and the ERA-40 analysis for humidity. For the observations, zero rainfall occurs for more than $20 \%$ of the time; hence, the first three deciles are associated with zero rainfall. Thus, to construct Fig. 4 from observed rainfall, we equally distribute the humidity anomalies for all occurrences of zero rainfall across the first three decile bins. It is evident that the lowest five deciles of the rainfall distribution are associated with anomalously low humidity, whereas the upper five deciles show increasingly positive humidity anomalies. The strongest increases in humidity with rainfall occur between 900 and $400 \mathrm{hPa}$, with the maximum anomaly occurring at about $750 \mathrm{hPa}$ for the tenth decile. It is noteworthy that the low-level humidity (below $900 \mathrm{hPa}$ ) is relatively constant with rainfall rate. It is also worth noting that there is an apparent increasing depth in the humidity anomalies, with increasing rainfall decile implying a moistening at low levels before that at upper levels as the rainfall rate increases.

The SP-CAM simulates the general pattern of humidity anomaly with rainfall decile reasonably well (Fig. 5a), although it is worth noting again that the decile thresholds for the SP-CAM rainfall (Table 1) diverge significantly from the observed, especially for the lowest and highest deciles. The magnitude of the humidity changes with rainfall appears to be overestimated, with both the negative and positive anomalies being significantly larger than observed. Also, the dry anomalies in the midtroposphere reach into a higher rainfall decile (decile 6) than the observed (decile 4). The gradual increase of humidity with increasing rainfall decile, including the vertical tilt from the lower to higher levels, is well reproduced. However, the maximum humidity anomaly is displaced upward from the observed level by about 100 to $650 \mathrm{hPa}$. The SP-CAM does, however, successfully reproduce the low variation of boundary layer humidity with rainfall.

The variation of humidity with rainfall rate in the CAM simulation (Fig. 5c) is significantly different from both the observations and the SP-CAM. Although similar in magnitude to the observations, the maximum moist anomaly is displaced to even higher levels (about $450 \mathrm{hPa}$ ) than in the SP-CAM. Perhaps the most notable model error occurs at the low levels near the surface, where at low rainfall deciles there is a strong negative humidity anomaly, while at high rainfall deciles there is a strong positive anomaly. This is in strong contrast to both the observations and the SP-CAM, which show little change of low-level humidity with rainfall. Another striking feature of the CAM simulation is the occurrence

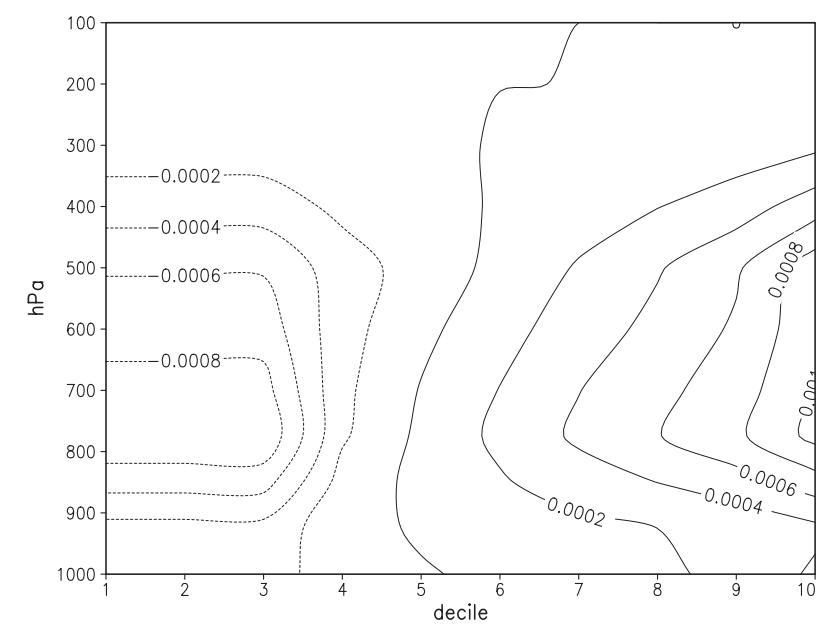

(a)

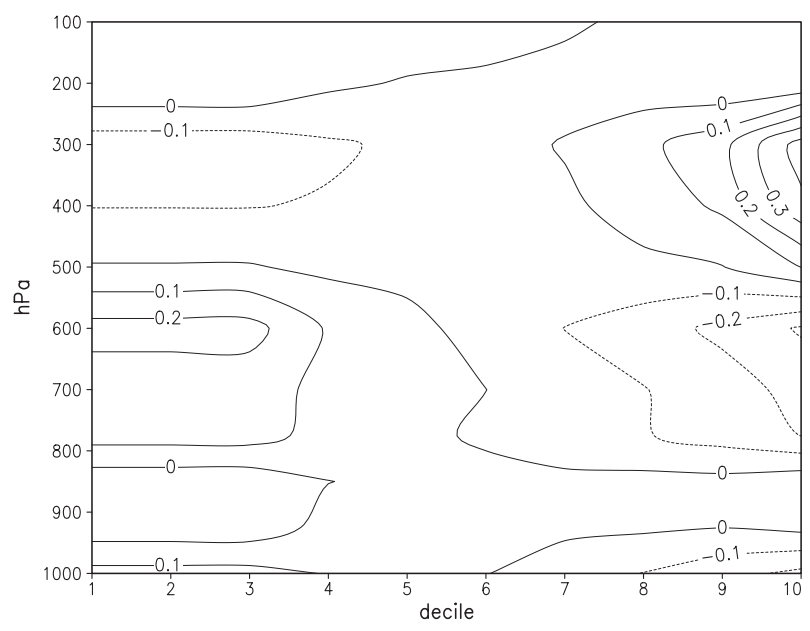

(b)

FIG. 4. (a) Mixing ratio ( $\left.\mathrm{CI}=0.0002 \mathrm{~kg} \mathrm{~kg}^{-1}\right)$ and (b) temperature $(\mathrm{CI}=0.1 \mathrm{~K})$ anomaly binned by rainfall deciles from observation for the domain shown in Fig. 3. 


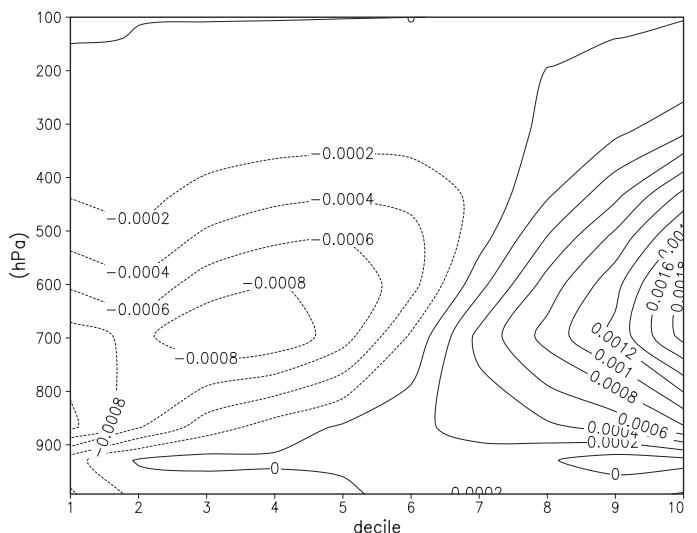

(a)

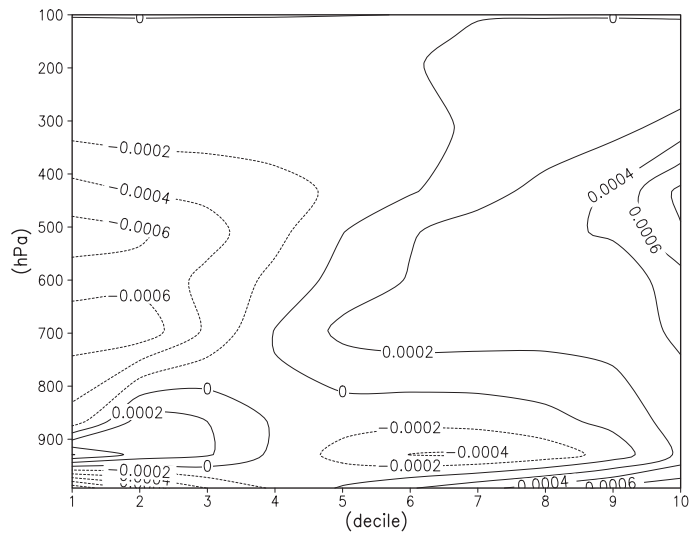

(c)

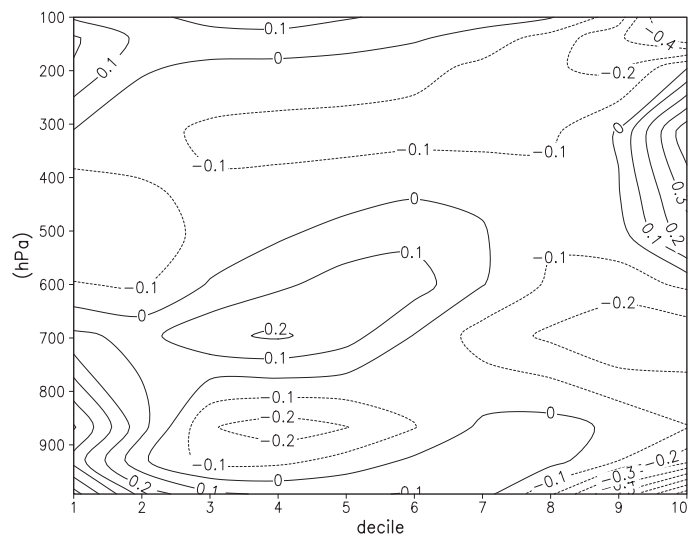

(b)

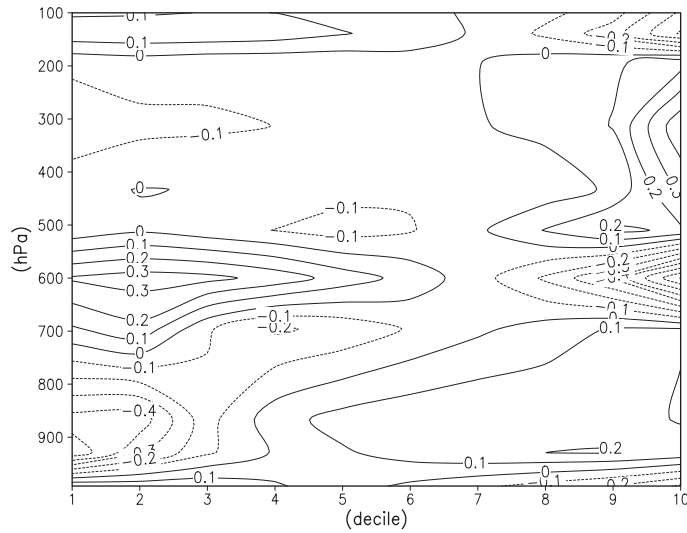

(d)

FIG. 5. (a),(c) Mixing ratio anomaly (CI $\left.=0.0002 \mathrm{~kg} \mathrm{~kg}^{-1}\right)$ and (b),(d) temperature anomaly $(\mathrm{CI}=0.1 \mathrm{~K})$, binned by rainfall deciles for (a),(b) SP-CAM and (c),(d) CAM.

of positive (negative) humidity anomalies at around $900 \mathrm{hPa}$ for below (above) median rainfall. For rainfall deciles above the median rainfall, dry anomalies in the low troposphere separate the moist anomalies between the surface and middle troposphere, which is a behavior different from that seen in observations and SP-CAM. Overall, the CAM only poorly represents the observed relationship between rainfall and tropospheric humidity anomaly.

\section{d. Relationship between precipitation and vertical profile of temperature}

The different treatments of convection in each simulation not only have different effects on the moisture distribution, but they also influence the vertical distribution of temperature. As with the moisture anomalies, the temperature anomalies are binned by deciles of rainfall rate for the observations (Fig. 4b) and the simulations (Figs. 5b,d). As expected, the temperature anomalies are small (about $0.2^{\circ} \mathrm{C}$ ), reflecting the relatively homogeneous temperature distribution in the tropics. Nevertheless, several interesting anomaly patterns do occur. At low rainfall rates the observations show a complicated vertical structure, with weak positive anomalies in the boundary layer underneath weak negative anomalies in the lower troposphere and stronger positive anomalies in the midtroposphere with weak negative anomalies in the upper troposphere. The stronger midlevel positive anomalies are consistent with subsiding motion in the midtroposphere, whereas the cold anomalies above the boundary layer are likely associated with shallow convection, which cools and moistens the low levels of the atmosphere near the top of the cloud layer (Nitta and Esbensen 1974), and those in the upper troposphere might be associated with a lack of high-level cloud. Active precipitation (deciles greater than 5) is associated with strong positive anomalies above $500 \mathrm{hPa}$ and with cold anomalies between 800-500 hPa and near the surface. The magnitude of these anomalies increases with rainfall amount. Importantly, the shape of the temperature anomaly patterns for high-rainfall deciles (greater than 5) is consistent 
with a heating-cooling couplet associated with stratiform precipitation within deep convective systems (e.g., Houze 1977) and with numerous other composites of observed tropical convective systems of various scales (e.g., Wheeler et al. 2000, their Fig. 7; Haertel and Kiladis 2004).

The models simulate the observed temperature anomalies with mixed success. For the lower deciles of precipitation (deciles less than 4), the SP-CAM (Fig. 5b) captures the warm-cold-warm-cold profile in the vertical, while the CAM displays this profile for deciles 3-5. More interesting, though, are the very strong differences in model behavior for the upper precipitation deciles. The SP-CAM reproduces the upper tropospheric warmlower tropospheric cold anomaly couplet well, although it exists only at the highest two deciles, whereas the observations show its onset around decile 7. The nearsurface cold anomaly is overestimated, indicating a perhaps too vigorous evaporation of rainfall, which may simply be due to the overestimation of rainfall rate at the high deciles (see Table 1). However, SP-CAM still has some success in representing the vertical structure of the temperature anomaly, which we hypothesize to be associated with the presence of stratiform precipitation processes for the higher rainfall deciles, indicating that the SP-CAM is able to simulate such processes.

The temperature anomaly structure at high rainfall in the CAM (Fig. 5d) does not resemble the observed structure. It is characterized by warm anomalies in both the upper and lower troposphere, with a very pronounced negative anomaly near $600 \mathrm{hPa}$ and a weaker cold anomaly near the surface. This anomaly structure resembles a convective heating profile (warm in the upper and lower troposphere), interrupted by strong cooling due to melting of precipitation in the midtroposphere. Because the vertical structure of temperature anomaly associated with precipitating convective systems has a profound influence on the interaction with the tropical circulation, it is intriguing to note that the model whose temperature anomaly resembles that of systems with a significant stratiform component simulates a robust MJO, while the model without such structure does not.

\section{e. Latent heat flux associated with deep convection}

Raymond et al. (2003) studied the convective forcing in the intertropical convergence zone (ITCZ) of the east Pacific. They used observations made during the East Pacific Investigation of Climate year 2001 process study (EPIC2001) project in the late summer and early fall of 2001 to investigate those factors important to the initiation of deep oceanic convection in the ITCZ. They found that developing deep convection occurs prefer- entially in locations with a deep layer that is conditionally unstable and is primarily generated and maintained by surface fluxes of heat and moisture (primarily latent heat flux). For an approximately 400-km-square region of the ITCZ, Raymond et al. (2003) observed a crude balance between the surface flux of moisture and heat (primarily latent heat) and the drying/cooling tendency induced by downdrafts (i.e., the boundary layer quasiequilibrium hypothesis; Raymond 1995); hence, a strong correlation was observed between the surface fluxes of heat and moisture and deep convection.

To study the relationship between latent heat flux and convection, composites of precipitation anomalies and latent heat flux anomalies for all occurrences of anomalous rainfall greater than $9.65 \mathrm{~mm} \mathrm{day}^{-1}$ are created. Note that the rainfall anomaly threshold is somewhat arbitrary, but is about one standard deviation of rainfall anomalies for observations (the standard deviation is calculated over the ocean grid points in the domain $12^{\circ} \mathrm{S}-12^{\circ} \mathrm{N}, 60^{\circ}-180^{\circ} \mathrm{E}$ and is about $10.87 \mathrm{~mm}^{-1 a y}{ }^{-1}$ for the SP-CAM and $6.5 \mathrm{~mm} \mathrm{day}^{-1}$ for the CAM). The results are not sensitive to any threshold greater than the one chosen here.

Figure 6 shows the evolution of the latent heat flux anomaly and precipitation anomaly (which is calculated using the same method as mixing ratio and temperature anomaly in Figs. 4 and 5) in relation to the strong rainfall events (rainfall anomaly greater than $9.65 \mathrm{~mm} \mathrm{day}^{-1}$ ). In the observations, the latent heat flux anomaly is seen to begin to increase about 7 days before peak rainfall and its peak is coincident with peak rainfall at day 0 . The latent heat flux anomaly then decreases rapidly after peak rainfall, with the increase and decrease about day 0 being fairly symmetric.

For the SP-CAM simulation, the latent heat flux begins to increase about 5 days before maximum rainfall, peaks about 1 day after maximum rainfall, and begins to decline rapidly after day +2 . The behavior of the latent heat flux in the SP-CAM is clearly more realistic but it displays a distinct 1-2-day lag relative to maximum rainfall. This behavior is reminiscent of a typical observed MJO event, with an increase in latent heat flux lagging the rainfall maximum by a few days (e.g., Hendon and Glick 1997). The observed lag of latent heat flux with respect to rainfall for the MJO is associated with the occurrence of maximum surface westerly winds that trail maximum convection by about 1 week (Hendon and Glick 1997). The occurrence of a phase lag in the SP-CAM using unfiltered daily data and the absence of such a lag in the latent heat flux anomaly in the unfiltered observations suggests that in the SP-CAM the lag likely stems from too much of the rainfall variability being driven by the overly strong MJO (cf. Fig. 2). 


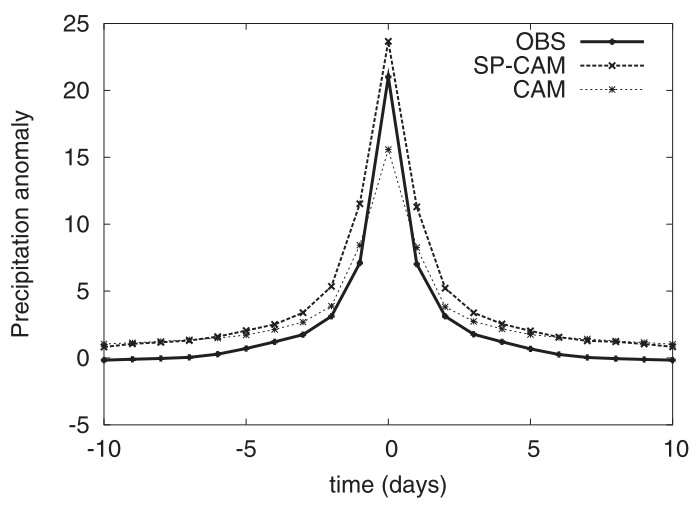

(a)

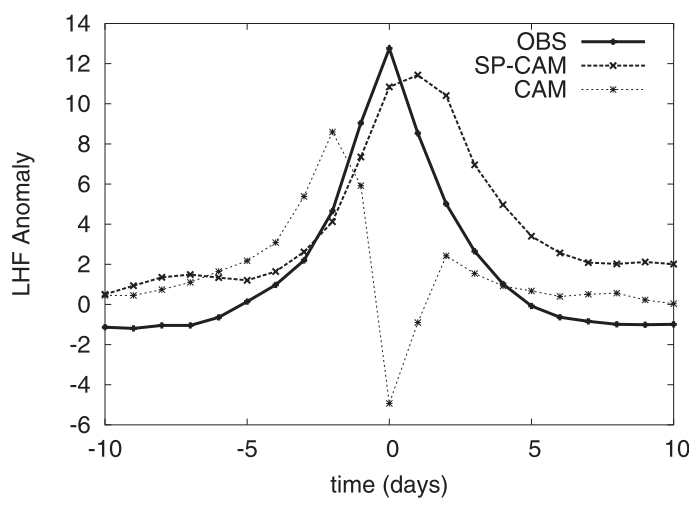

(b)

FIG. 6. (a) Daily mean precipitation anomaly $\left(\mathrm{mm} \mathrm{day}^{-1}\right)$ and (b) daily mean latent heat flux anomaly $\left(\mathrm{W} \mathrm{m}^{-2}\right)$ composited by the occurrence of daily mean precipitation anomaly greater than $9.65 \mathrm{~mm} \mathrm{day}^{-1}$ for observation, SP-CAM, and CAM for the domain shown in Fig. 3.

In contrast with the observation and SP-CAM, the latent heat flux in the CAM simulation peaks 2.5 days before the rainfall maximum and dramatically plunges at day 0 . Precipitation in the CAM is positively correlated with the boundary layer moisture (Fig. 5), and the strong increase in boundary humidity appears to act to decrease the surface latent heat flux at the time of maximum rainfall. The behavior of the latent heat flux in the CAM is clearly unrealistic, and from the perspective of boundary layer quasi-equilibrium (Raymond 1995), the behavior of the latent heat flux in the CAM would appear to act as a throttle for development of organized deep convection. The result in the CAM (minimum latent heat flux at time of peak rainfall) indicates that some of the fundamental assumptions about the representation of convection in the CAM are flawed.

\section{MJO-related convection features}

We have so far focused on the behavior of daily averaged tropical oceanic rainfall and the associated variations of humidity, temperature, and surface fluxes on a grid of roughly $250 \mathrm{~km}$. We now will attempt to relate this daily-mean gridpoint behavior to the simulation of the MJO, which of course displays strong spatial and temporal coherence. To isolate rainfall events that are related to the MJO, we filter precipitation at each model and observed grid point to eastward-propagating disturbances for zonal wavenumbers 1-5 with period 30-90 days (e.g., Wheeler and Kiladis 1999). Similar to Benedict and Randall (2007), MJO-filtered precipitation at each grid point is chosen as the variable on which MJO events are based. To explore connections between atmospheric dynamics and convection during the evolution of the MJO, we composite a variety of fields relative to the
MJO-filtered precipitation (defined as $\mathrm{MJO}$-prec) at each ocean grid point in the domain of $12^{\circ} \mathrm{S}-12^{\circ} \mathrm{N}$, $60^{\circ}-180^{\circ} \mathrm{E}$. At each grid point, we define an MJO event as an occurrence of MJO-prec that exceeds 2.5 standard deviations (the standard deviation is equal to about $4.5 \mathrm{~mm}$ day $^{-1}$ for SP-CAM and $2.1 \mathrm{~mm} \mathrm{day}^{-1}$ for the CAM). Lag and lead composites of anomaly fields are formed relative to the time of maximum MJO-prec that exceeds 2.5 standard deviations at each ocean grid point. In this fashion, we build up a one-dimensional (height) lead-lag composite of the evolution of the MJO. We mainly compare the model simulations to what was observed in Benedict and Randall (2007).

The mixing ratio composite for the MJO is shown in Fig. 7a for SP-CAM. Humidity begins to increase above the boundary layer about 15 days before the peak rainfall and then increases over an increasingly deep layer, with the maximum value occurring in the midtroposphere at lag 0 (when MJO-prec peaks). Little variation of boundary layer moisture is seen. This progressive moistening of the low to midtroposphere is consistent with a similar development of rising motion (Fig. 7b). About 10 days after peak precipitation, drying is first accomplished in the lower troposphere and then expands vertically upward with time. These features of moistening and drying are similar to the findings of Benedict and Randall (2007), who studied the observed characteristics of the MJO relative to maximum rainfall. They found that the time for the discharge of moisture is about half of that for recharge. Drying in SP-CAM happens rather later, around day 8 , and returns to the anomalously dry state by day 13 , and the drying rate after the rainfall maximum is about $2 / 3$ of that for the moistening rate before the rainfall maximum. The lag of upper tropospheric humidity relative to that in the 


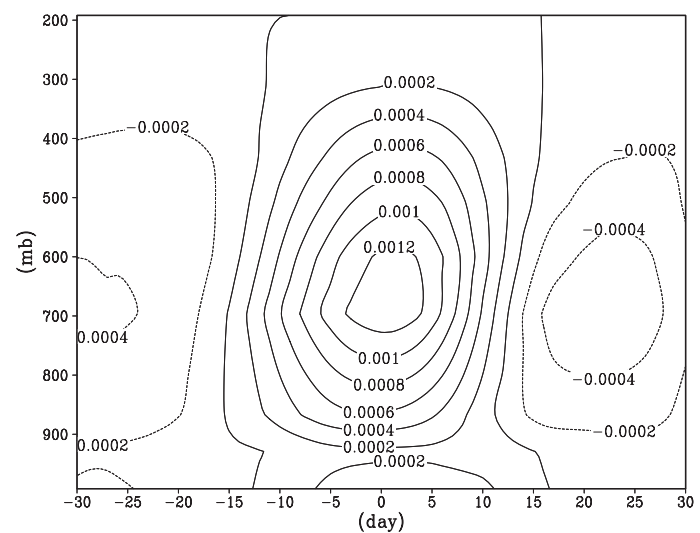

(a)

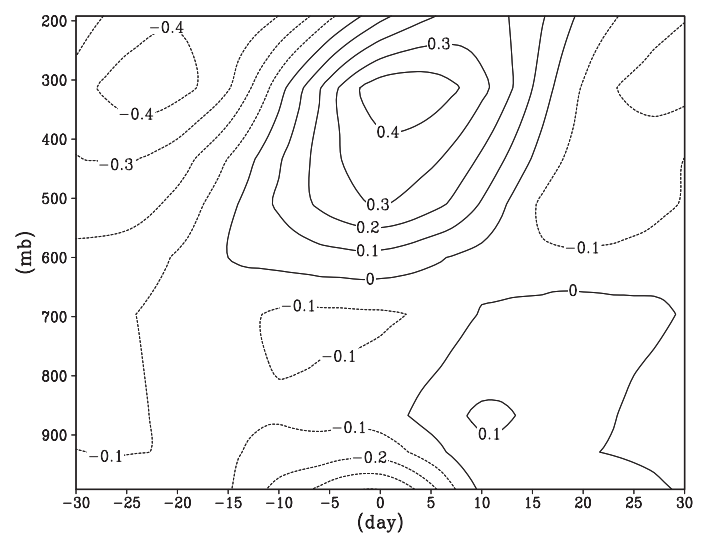

(c)

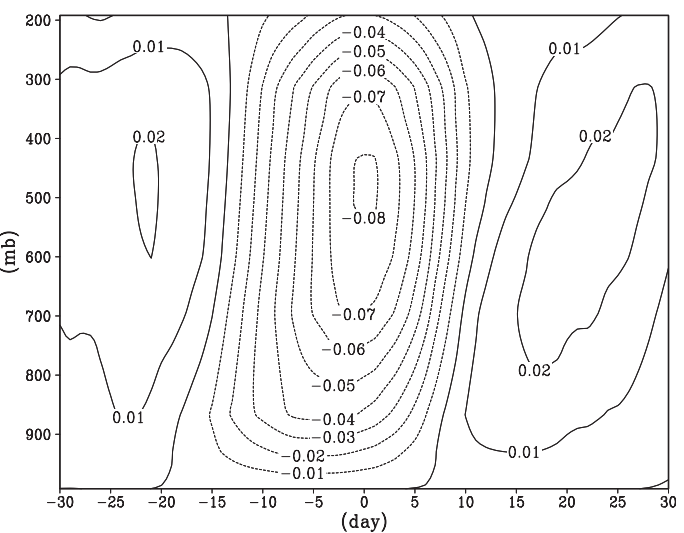

(b)

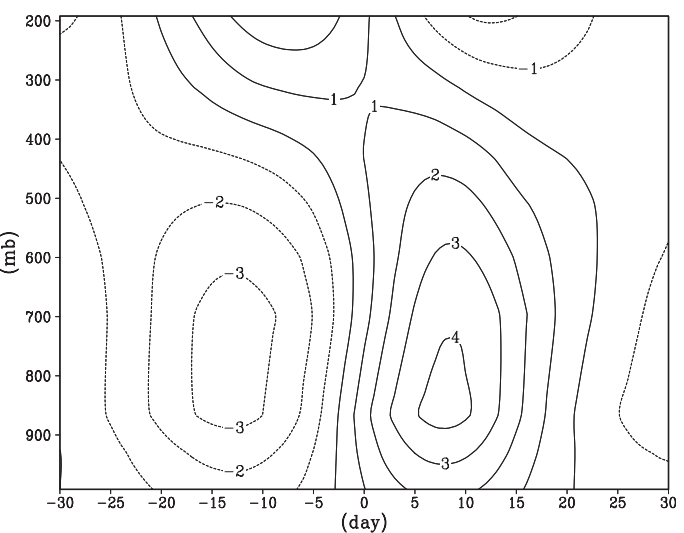

(d)

FIG. 7. Daily anomalies of (a) mixing ratio $\left(\mathrm{CI}=0.0002 \mathrm{~kg} \mathrm{~kg}^{-1}\right)$, (b) vertical velocity $\left(\mathrm{CI}=0.01 \mathrm{~Pa} \mathrm{~s}^{-1}\right)$, (c) temperature $(\mathrm{CI}=0.1 \mathrm{~K})$, and $(\mathrm{d})$ zonal wind $\left(\mathrm{CI}=1 \mathrm{~m} \mathrm{~s}^{-1}\right)$ composited relative to MJO-prec greater than 2.5 times std dev for SP-CAM for the domain shown in Fig. 3.

lower troposphere is surprisingly subtle here in SP-CAM (about 2 days) relative to observations (about 7 days) (Benedict and Randall 2007), possibly because for SP-CAM, 4-km resolution might not be able to resolve shallow convection sufficiently well to produce an earlier moistening of the lower troposphere (as in the observed) before the maximum precipitation occurs. This also indicates that in SP-CAM premoistening of shallow convection may not be a critical factor for the strong MJO, which has been emphasized as an important feature in observed MJO in Benedict and Randall (2007).

Figure $7 \mathrm{c}$ shows the temperature anomaly relative to the MJO-prec. Between days -18 and -10 , there is a negative temperature anomaly in the lower troposphere, which is consistent with a steadily increasing moisture anomaly possibly associated with shallow convection, as shown in Figs. 7a,b. With time, the condensation heat release from deep convection likely offsets the adiabatic cooling of ascending motion, and the temperature anomaly becomes positive and reaches into the middle and upper troposphere at day 0 . At the time of maximum precipitation, the warm anomaly reaches $0.4^{\circ}$ at the level of $300 \mathrm{hPa}$. Meanwhile, cold anomalies occur in the lower troposphere between days -15 and +2 . Similar to the precipitation decile compositing in Fig. 5, the temperature anomaly profile at day 0 is consistent with top-heavy diabatic heating as a result of stratiform precipitation areas within deep convective systems.

The zonal wind composite (Fig. 7d) indicates that MJO convection is associated with a deep baroclinic disturbance with a transition from surface easterly to westerly between days -5 and 0 . The transition from easterly to westerly anomalies in Fig. $7 \mathrm{~d}$ starts near the surface and the maximum westerlies occur at $800 \mathrm{hPa}$ at day 8 . The baroclinic nature of the zonal wind anomaly is consistent with the zonal wind being driven by the deep diabatic heating associated with latent heat release (e.g., Gill 1980).

We also applied the MJO filtering and compositing to the CAM simulations. We recall that there is no signal of the MJO in the CAM simulation (cf. Fig. 2). Hence, the 


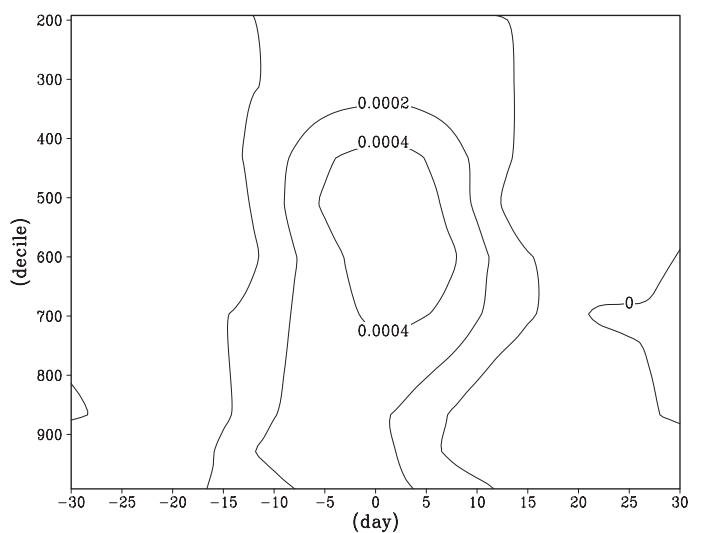

(a)

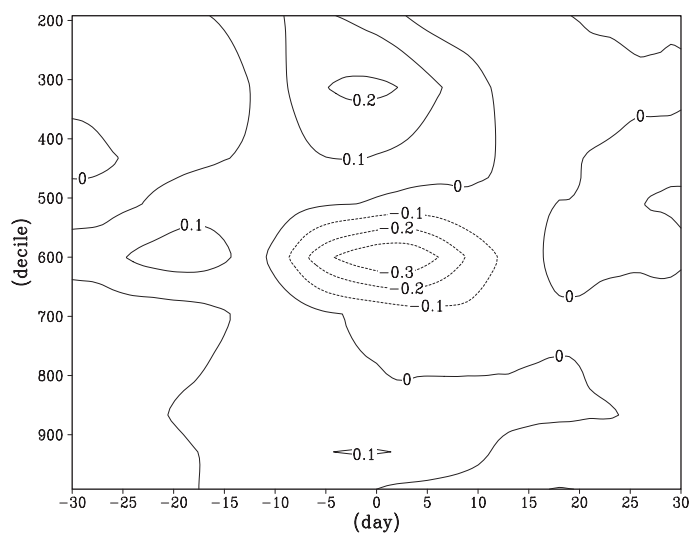

(c)

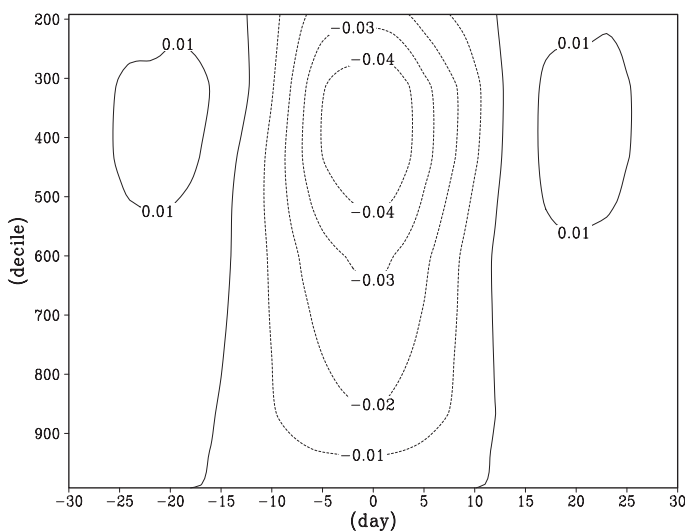

(b)

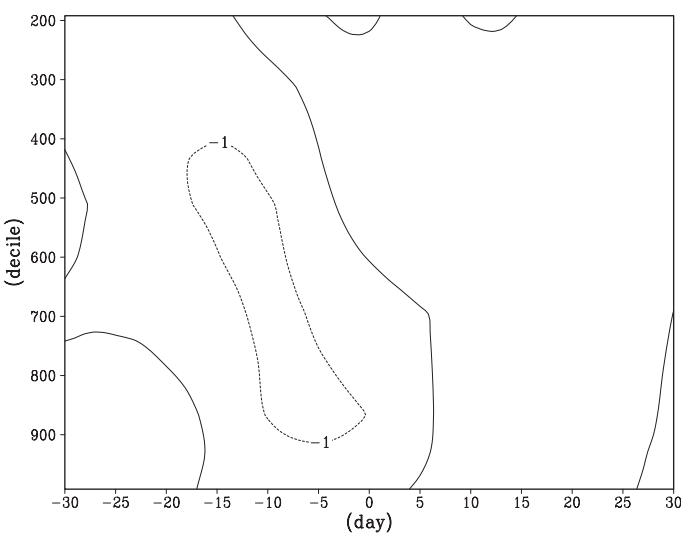

(d)

FIG. 8. As in Fig. 7, but for CAM.

filtering to MJO wavenumbers and frequencies essentially reveals the behavior of randomly occurring largescale rainfall events. Nonetheless, the composites based on MJO filtered data are of interest because they reflect the evolution of large-scale convection in the CAM even though convection in the CAM does not have a propensity to propagate eastward.

Figure 8 shows composites relative to the MJO-prec for the CAM (recall that the 2.5 standard deviation threshold is $2.1 \mathrm{~mm}^{-1 a y}{ }^{-1}$ as compared to $4.5 \mathrm{~mm}_{\text {day }}{ }^{-1}$ for the SP-CAM). The composite vertical velocity anomaly (Fig. 8b) has an amplitude about half that in SP-CAM and it peaks higher in the troposphere. The weaker anomalies in vertical motion (and all other composited variables) are likely due to weaker convection in CAM model. Consistent with the vertical velocity field, the mixing ratio anomaly (Fig. 8a) has a moist anomaly maximum at $550 \mathrm{hPa}$ when the precipitation reaches a maximum. The moisture anomaly in Fig. $8 \mathrm{a}$ is about 3 times smaller compared to the value in SP-CAM. The temperature anomaly (Fig. 8c) has positive centers in the upper troposphere (about $300 \mathrm{hPa}$ ) and lower troposphere and a strong negative center near $600 \mathrm{hPa}$, which is similar to the profile for the highest rainfall decile (Fig. 5d). The lack of any structure indicative of a stratiform heating profile appears to be the main factor that accounts for the difference in the temperature profile from SP-CAM.

The composite zonal wind anomaly for the CAM is displayed in Fig. 8d. Easterly winds are dominant between days -15 and 5 in the low to midtroposphere, reaching their maximum strength at about $900 \mathrm{hPa}$ at day -5 . With the same contour interval as SP-CAM, westerly winds are weak and mainly occur at day 5 in the lower troposphere. However, the baroclinic structure of the zonal wind seen in SP-CAM is hardly evident, indicating that the zonal wind anomaly is decoupled from the convective heating source.

Figure 9 shows the MJO-filtered latent heat flux anomaly. Unlike in Fig. 6 where the compositing was 


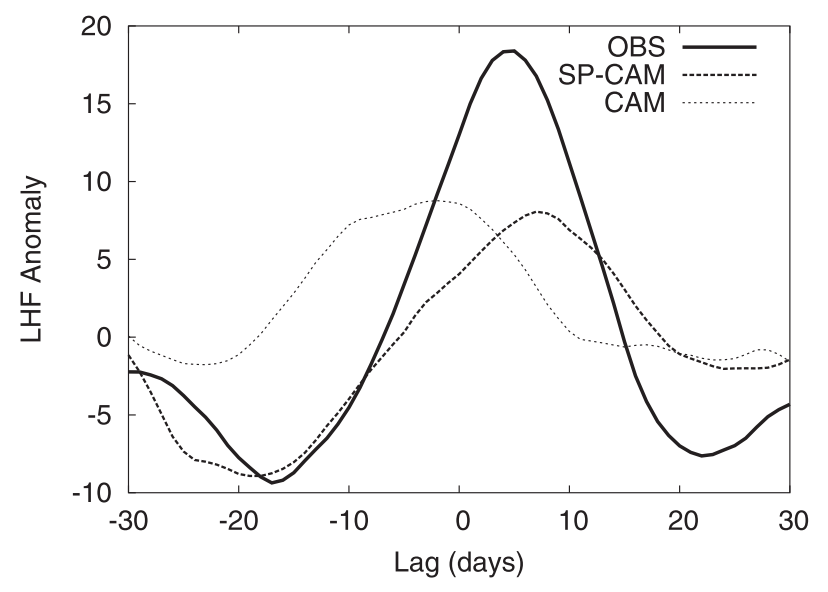

FIG. 9. Daily LHFLX anomaly $\left(\mathrm{W} \mathrm{m}^{-2}\right)$ composited relative to MJO-prec greater than $2.5 \mathrm{std}$ dev for SP-CAM, CAM, and observations for the domain shown in Fig. 3.

based on any strong rainfall event using unfiltered data, the observations for the MJO-filtered case show a latent heat flux maximum at about day +7 (cf. Hendon and Glick 1997). This lag is well reproduced by the SP-CAM, even though the amplitude of the anomaly is not. The CAM shows a reduction in latent heat flux after day 0 , but care must be taken when interpreting this because of the use of filtering as applied to the CAM that has no MJO.

We now attempt to relate the evolution of the structure of the anomalies of moisture, temperature, and vertical velocity associated with the MJO to that inferred from the daily behavior based on the unfiltered analyses in sections $3 \mathrm{c}$ and $3 \mathrm{~d}$. For instance, in both simulations, the vertical profiles of temperature, humidity, and vertical velocity at the time of maximum MJO rainfall appear to be consistent with the profiles developed using unfiltered data associated with rainfall rates in the upper deciles. To confirm this inference, we compute composites of the occurrence of each unfiltered rainfall decile when MJO-prec at each gridpoint exceeds 2.5 standard deviations. That is, at each grid point when the MJO-prec exceeds 2.5 standard deviations, we accumulate the occurrence of the actual unfiltered daily rainfall rate in each decile. Then, we combine adjoining decile thresholds to form quintiles to compact and smooth the results. We form the accumulation at lags from -30 days to +30 days, thereby developing a composite of the rate of occurrence of each rainfall quintile for the evolution of the MJO.

Figure 10a shows that for SP-CAM the rate of occurrence of the highest rainfall quintile peaks at about $50 \%$ (up from a baseline value of $20 \%$ ) at day 0 (the time of maximum MJO-prec), whereas the lowest three quintiles at day 0 are at a weak minimum $(10 \%$, about half of the baseline rate). Interestingly, the rate of occurrence of the fourth quintile peaks at about day -10 and then declines gradually through day +10 . At day +20 , the fifth quintile of precipitation reduces to the minimum and yields its dominant role to first quintile precipitation, indicating that in the dry stage of the $\mathrm{MJO}$, the weakest precipitation quintile occurs most. Obviously, for SP-CAM, peak MJO-prec (day 0) is dominated by cases in which the precipitation rate is in the fifth quintile and the evolution of the temperature, humidity, and vertical velocity through the life cycle of the MJO (Fig. 7) can thus be inferred from the associated profiles for each rainfall quintile (Fig. 5): the evolution of the MJO in the SP-CAM is associated with a slow buildup of deepening convection that culminates at day 0 with stratiform-dominated profiles of humidity, temperature, and vertical velocity.

The associated MJO-filtered composite for the CAM has some marked difference (Fig. 10b). At the time of maximum filtered rainfall (day 0), the rainfall rates are dominated by the highest quintile (with a peak value of $45 \%$ ), but there is no indication of a preceding shift from the lower to the fourth quintile prior to day 0 . The evolution of the profiles of temperature, humidity, and vertical velocity for the MJO-filtered composites from the CAM are thus consistent with a strong switch to the highest quintile rainfall rates at day 0 , and no evolution through the lower quintiles occurs in the leadup to peak filtered precipitation. Furthermore, in the dry stage, the first quintile precipitation fails to dominate at day +20 , when the fifth quintile precipitation is the minimum.

Observations (Fig. 10c) shows a similar evolution of the quintile occurrences to those in SP-CAM, with peak MJO rainfall being dominated by the fifth quintile and a minimum for the lowest three quintiles at day 0 , and a slight preceding peak for the fourth quintile at day -10 . This evolution of quintile occurrences for observations is thus consistent with the vertical development of convection in the lead-up to peak MJO rainfall, as well as with a stratiform rainfall regime dominating at day 0 . At day +20 , the weakest rainfall quintile plays a dominant role in the dry stage.

\section{Discussion and conclusions}

The behavior of convection and the MJO are investigated in two versions of the Community Atmospheric Model (CAM): the standard model with the Zhang and McFarlane (1995) convection parameterization scheme, simply called CAM, and a "multiscale modeling framework," in which the cumulus parameterization has been replaced with a cloud-resolving model, called SP-CAM. Wavenumber-frequency spectrum analysis 


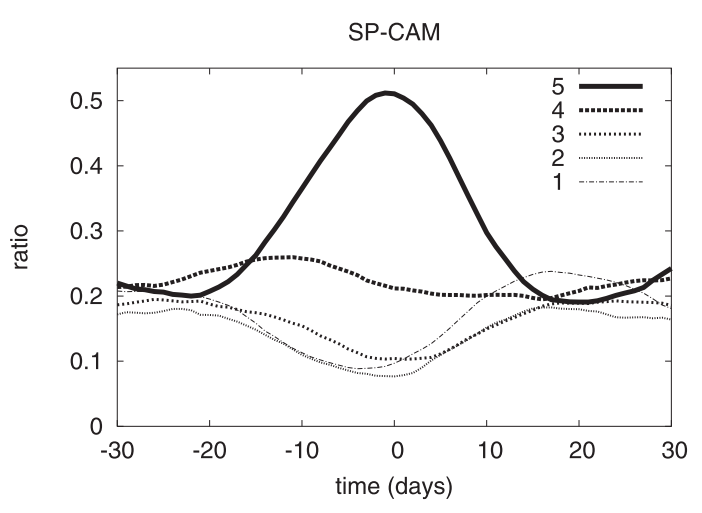

(a)

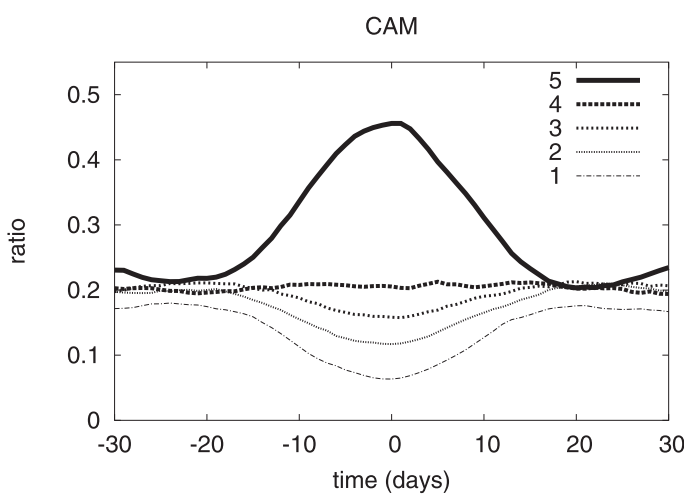

(b)

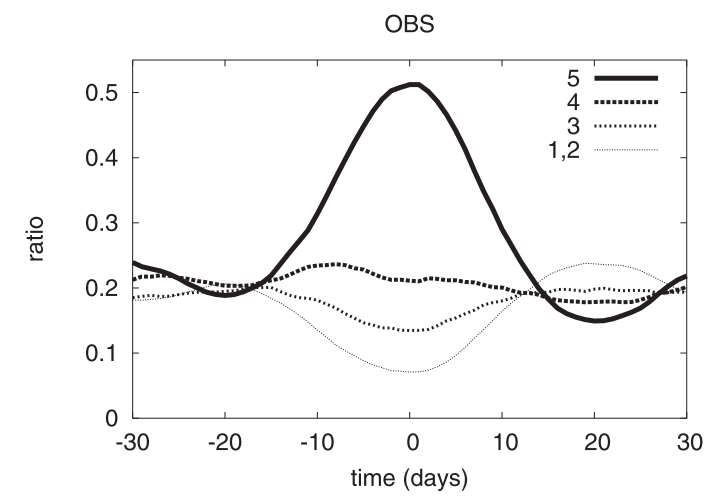

(c)

FIG. 10. Frequency of occurrence of precipitation in each quintile composited relative to the occurrence of MJO-prec exceeding 2.5 std dev for (a) SP-CAM, (b) CAM, and (c) observations.

shows that there is a strong $\mathrm{MJO}$, with pronounced spectral peaks in both precipitation and U850 fields, in the SP-CAM, but the MJO is completely absent in the CAM simulation. In this study, we compare aspects of the behavior of convection in the two simulations with the aim of understanding which aspects of moist convection are potentially important for simulations of the MJO.

We conclude that the following features of convection are likely affecting the difference in MJO simulations in the two models:

1) In SP-CAM, rainfall exhibits a strongly exponential increase with increasing column-integrated relative humidity, albeit with peak rainfall having too moist an atmosphere as compared to observations. This sensitivity of rainfall to column-integrated humidity is consistent with the strongest convection having the most humid conditions. In the CAM, it tends to rain at too low a saturation fraction, and high saturation fraction/ high rainfall rates are not achieved. This indicates that the CAM model does not require high column humidity to precipitate; at the same time, the buildup of high column humidity is prevented, presumably through the early triggering of convection. These findings are consistent with a large number of earlier studies, in particular Wang and Schlesinger (1999), who showed that delaying the onset of convection to moister conditions generally improved the simulation of the MJO. The SP-CAM appears to have the mechanisms for such a delay built into its formulation.

There is, however, more than one possible explanation for the SP-CAM behavior. One interpretation of the results is that the replacement of the parameterized convection with a CRM leads to the correct simulation of convection in the model and that this leads to the improved simulation of the MJO. However, some of our findings indicate that the onset of convection in the SP-CAM is delayed to too high saturation fractions. When precipitation finally occurs, it occurs with too high an intensity and with a strong stratiform heating component. We speculate that the 
poor resolution of the CRM embedded in each grid box $(4 \mathrm{~km})$ prevents convection from occurring until the column has become very moist. The poor resolution might also cause too much of the rainfall to come from stratiform processes. The combination of the "delay" in convection and the largely stratiform nature of the resulting precipitation then leads to the simulation of a much stronger than observed MJO. With the data available to us, it is difficult to tell which of those two alternative explanations is more likely; this will be the subject of further study.

2) In SP-CAM, heavy precipitation is associated with a positive-negative temperature anomaly couplet during heavy rainfall, possibly indicative of the presence of a stratiform diabatic heating profile. Such diabatic heating structures have been shown to project onto slower horizontally propagating wave modes (e.g., Fulton and Schubert 1985 and Mapes 2000). In contrast, in the CAM simulation, the temperature profile is more indicative of a convective-dominated heating profile that will project onto faster modes.

Lin et al. (2004) found that the observed profile of heating through the troposphere for the MJO is top heavy, and stratiform precipitation (heating the upper troposphere and cooling the lower troposphere) contributes more to the intraseasonal rainfall variations than it does to seasonal-mean rainfall. The role of the vertical heating profile in setting the strength and phase speed of intraseasonal oscillations has been studied in several works. For instance, a "stratiform instability" mechanism has been proposed by Mapes (2000). Yamasaki (1969) found in numerical modeling studies that some tropical systems are unstable only if the cumulus heating profile has a maximum in the upper troposphere. Lin et al. (2004) argued that a systematic lack of stratiformlike heating in models could be hypothesized to contribute to too weak intraseasonal variability and too fast phase speeds.

Recently, there has been more development of the theory of stratiform instability (Mapes 2000). A work by Kuang (2008) found that the effect of midtroposphere humidity on the depth of convection (moisture-stratiform instability) is the main mechanism for convectively coupled wave development in the cloud-resolving model. Also, a paper by Raymond and Fuchs (2009) related the MJO to the completely distinct moist modes, which are inherently slow moving. The relationship of the MJO in SP-CAM to the abovementioned instabilities will be a subject of our future studies.

3) For observations and the SP-CAM, strong rainfall events (based on unfiltered gridpoint rainfall) are associated with increased latent heat flux, whereas for the CAM, strong rainfall is associated with decreased latent heat flux. The latent heat flux in the SP-CAM is consistent with the notion of boundary layer quasi-equilibrium, whereby deep convection is controlled by the moistening and destabilizing effects of the surface flux of heat and moisture that offsets the drying and stabilizing tendency induced by unsaturated convective downdrafts (e.g., Raymond et al. 2003). The decrease of latent heat flux at the time of maximum rainfall in the CAM, which appears to stem from a spuriously strong dependence of deep convection on high surface humidity, therefore appears to act as a throttle for the development of organized deep convection in the CAM.

In conclusion, this study has developed a number of innovative diagnostic methods, which, when applied to two models, appear to show a strong relationship to those models' ability to simulate the MJO. The advantages of these new diagnostics over previous techniques are that (i) they are very simple and (ii) they do not require the presence of an $\mathrm{MJO}$ in the model under investigation. The disadvantage of the methods proposed here is that the connection of the model errors revealed by them to the MJO simulation remains based on circumstantial evidence only. Applying the techniques to only two models is obviously insufficient to go beyond the circumstantial. A natural extension of this work is therefore to apply the techniques to a wider range of models. Overall we consider the techniques applied here to be a promising tool both for identifying the features of convective behavior that are key to the MJO and for evaluating their representation in models.

Acknowledgments. We are most grateful to David Raymond, Matt Wheeler, and Noel Davidson for their perceptive critiques and constructive suggestion of the manuscript. We thank Roger Marchand for providing the data for the two model simulations. We thank the CMMAP team for their support and in particular David Randall, Tom Ackerman, Roger Marchand, and Robert Pincus for discussions on the evaluation of the SP-CAM model. We thank Zhiming Kuang and an anonymous reviewer for their constructive review comments on the manuscript.

\section{REFERENCES}

Adler, R. F., and Coauthors, 2003: The version-2 Global Precipitation Climatology Project (GPCP) monthly precipitation analysis (1979-present). J. Hydrometeor., 4, 1147-1167.

Benedict, J., and D. Randall, 2007: Observed characteristics of the MJO relative to maximum rainfall. J. Atmos. Sci., 64, 2332-2354. 
Bessafi, M., and M. C. Wheeler, 2006: Modulation of South Indian Ocean tropical cyclones by the Madden-Julian oscillation and convectively coupled equatorial waves. Mon. Wea. Rev., 134, 638-655.

Bretherton, C., M. E. Peters, and L. Back, 2004: Relationships between water vapor path and precipitation over the tropical oceans. J. Climate, 17, 1517-1528.

Collins, W. D., and Coauthors, 2004: Description of the NCAR Community Atmosphere Model (CAM 3.0). NCAR Tech. Rep. NCAR/TN-464+STR, 210 pp.

DeMott, C., D. Randall, and M. Khairoutdinov, 2007: Convective precipitation variability as a tool for general circulation model analysis. J. Climate, 20, 91-112.

Fulton, S., and W. Schubert, 1985: Vertical normal mode transforms: Theory and application. Mon. Wea. Rev., 113, 647-658.

Gill, A. E., 1980: Some simple solutions for heat-induced tropical circulation. Quart. J. Roy. Meteor. Soc., 106, 447-462.

Goswami, B. N., 2005: South Asian monsoon. Intraseasonal Variability in the Atmosphere-Ocean Climate System, W. K. M. Lau and D. E. Waliser, Eds., Springer Praxis, 19-61.

Grabowski, W. W., 2001: Coupling cloud processes with the largescale dynamics using the Cloud-Resolving Convection Parameterization (CRCP). J. Atmos. Sci., 58, 978-997.

Haertel, P. T., and G. N. Kiladis, 2004: Dynamics of 2-day equatorial waves. J. Atmos. Sci., 61, 2707-2721.

Hayashi, Y., and A. Sumi, 1986: The 30-40-day oscillations simulated in an "aquaplanet" model. J. Meteor. Soc. Japan, 64, 451-466.

Hendon, H. H., and B. Liebmann, 1990: Composite study of onset of the Australian summer monsoon. J. Atmos. Sci., 47, $2227-$ 2240.

—_, and J. Glick, 1997: Intraseasonal air-sea interaction in the tropical Indian and West Pacific Oceans. J. Climate, 10, 647-661.

_ M. C. Wheeler, and C. Zhang, 2007: Seasonal dependence of the MJO-ENSO relationship. J. Climate, 20, 531-543.

Houze, R. A., Jr., 1977: Structure and dynamics of a tropical squallline system. Mon. Wea. Rev., 105, 1540-1567.

Kessler, W. S., M. J. McPhaden, and K. M. Weickmann, 1995: Forcing of intraseasonal Kelvin waves in the equatorial Pacific. J. Geophys. Res., 100, 10 613-10 631.

Khairoutdinov, M., and D. Randall, 2001: A cloud resolving model as a cloud parameterization in the NCAR Community Climate System Model: Preliminary results. Geophys. Res. Lett., 28, 3617-3620.

,-- , and C. DeMott, 2005: Simulations of the atmospheric general circulation using a cloud-resolving model as a superparameterization of physical processes. J. Atmos. Sci., 62, 2136-2154.

Kuang, Z., 2008: A moisture-stratiform instability for convectively coupled waves. J. Atmos. Sci., 65, 834-854.

Lau, N.-C., I. M. Held, and J. D. Neelin, 1988: The Madden-Julian oscillation in an idealized general circulation model. J. Atmos. Sci., 45, 3810-3831.

Liebmann, B., H. Hendon, and J. Glick, 1994: The relationship between tropical cyclones of the western Pacific and Indian Oceans and the Madden-Julian oscillation. J. Meteor. Soc. Japan, 72, 401-412.

Lin, J., B. Mapes, M. Zhang, and M. Newman, 2004: Stratiform precipitation, vertical heating profiles, and the Madden-Julian oscillation. J. Atmos. Sci., 61, 296-309.

-, and Coauthors, 2006: Tropical intraseasonal variability in 14 IPCC AR4 climate models. Part I: Convective signals. J. Climate, 19, 2665-2690.
Madden, R. A., and P. R. Julian, 1994: Observations of the 40-50day tropical oscillation-A review. Mon. Wea. Rev., 122, 814-837.

Maloney, E., and D. Hartmann, 2001: The sensitivity of intraseasonal variability in NCAR CCM3 to changes in convective parameterization. J. Climate, 14, 2015-2034.

Mapes, B., 2000: Convective inhibition, subgrid-scale triggering energy, and stratiform instability in a toy tropical wave model. J. Atmos. Sci., 57, 1515-1535.

Marchand, R. T., J. Haynes, G. Mace, T. Ackerman, and G. Stephens, 2009: A comparison of simulated cloud radar output from the multiscale modeling framework global climate model with CloudSat cloud radar observations. J. Geophys. Res., 114, D00A20, doi:10.1029/2008JD009790.

McPhaden, M. J., 2008: Evolution of the 2006-2007 El Niño: The role of intraseasonal to interannual time scale dynamics. $A d v$. Geosci., 14, 219-230.

Nitta, T., and S. K. Esbensen, 1974: Heat and moisture budget analyses using BOMEX data. Mon. Wea. Rev., 102, 17-28.

Raymond, D. J., 1995: Regulation of moist convection over the West Pacific warm pool. J. Atmos. Sci., 52, 3945-3959.

_ 2007: Testing a cumulus parametrization with a cumulus ensemble model in weak-temperature-gradient mode. Quart. J. Roy. Meteor. Soc., 133, 1073-1085.

— , and Z. Fuchs, 2009: Moisture modes and the Madden-Julian oscillation. J. Climate, 22, 3031-3046.

—, G. B. Raga, C. S. Bretherton, J. Molinari, C. López-Carrillo, and Z. Fuchs, 2003: Convective forcing in the intertropical convergence zone of the eastern Pacific. J. Atmos. Sci., 60, 2064-2082.

Salby, M. L., and H. H. Hendon, 1994: Intraseasonal behavior of winds, temperature, and motion in the tropics. J. Atmos. Sci., 51, 2207-2224.

Sherwood, S., 1999: Convective precursors and predictability in the tropical western Pacific. Mon. Wea. Rev., 127, 29772991.

Slingo, J. M., and Coauthors, 1996: Intraseasonal oscillations in 15 atmospheric general circulation models: Results from an AMIP diagnostic subproject. Climate Dyn., 12, 325-357.

Tokioka, T., K. Yamazaki, A. Kitoh, and T. Ose, 1988: The equatorial 30-60-day oscillation and the Arakawa-Schubert penetrative cumulus parameterization. J. Meteor. Soc. Japan, 66, 883-901.

Uppala, S. M., and Coauthors, 2005: The ERA-40 re-analysis. Quart. J. Roy. Meteor. Soc., 131, 2961-3012.

Waliser, D. E., K. M. Lau, W. Stern, and C. Jones, 2003: Potential predictability of the Madden-Julian oscillation. Bull. Amer. Meteor. Soc., 84, 33-50.

Wang, W., and M. E. Schlesinger, 1999: The dependence on convective parameterization of the tropical intraseasonal oscillation simulated by the UIUC 11-layer atmospheric GCM. J. Climate, 12, 1423-1457.

Weickmann, K. M., G. R. Lussky, and J. E. Kutzbach, 1985: Intraseasonal (30-60 day) fluctuations of outgoing longwave radiation and 250-mb streamfunction during northern winter. Mon. Wea. Rev., 113, 941-961.

Wheeler, M., and G. Kiladis, 1999: Convectively coupled equatorial waves: Analysis of clouds and temperature in the wavenumberfrequency domain. J. Atmos. Sci., 56, 374-399.

_ Intraseasonal Variability in the Atmosphere-Ocean Climate System, W. K. M. Lau and D. E. Waliser, Eds., Springer Praxis, 125-173. 
- G. Kiladis, and P. Webster, 2000: Large-scale dynamical fields associated with convectively coupled equatorial waves. J. Atmos. Sci., 57, 613-640.

Yamasaki, M., 1969: Large-scale disturbances in the conditionally unstable atmosphere in low latitudes. Pap. Meteor. Geophys. 20, 289-336.

Yasunari, T., 1979: Cloudiness fluctuations associated with the Northern Hemisphere summer monsoon. J. Meteor. Soc. Japan, 57, 227-242.

Yu, L., X. Jin, and R. A. Weller, 2008: Multidecade global flux datasets from the Objectively Analyzed Air-Sea Fluxes
(OAFlux) Project: Latent and sensible heat fluxes, ocean evaporation, and related surface meteorological variables. Woods Hole Oceanographic Institution OAFlux Project Tech. Rep. OA-2008-01, 64 pp.

Zhang, C., and Coauthors, 2006: Simulations of the Madden-Julian oscillation in four pairs of coupled and uncoupled global models. Climate Dyn., 27, 573-592.

Zhang, G. J., and N. A. McFarlane, 1995: Sensitivity of climate simulations to the parameterization of cumulus convection in the Canadian Climate Centre general circulation model. Atmos.-Ocean, 33, 407-446. 